\title{
Thromboerythrocytes
}

\section{In Vitro Studies of a Potential Autologous, Semi-artificial Alternative to Platelet Transfusions}

Barry S. Coller, Karen T. Springer, Juerg H. Beer, Narla Mohandas, Lesley E. Scudder, Karin J. Norton, and Sharon M. West Division of Hematology, State University of New York at Stony Brook, Stony Brook, New York 11794; Laboratory for Thrombosis Research, University Hospital of Bern, CH-3010 Bern, Switzerland; and Division of Cell and Molecular Biology, Lawrence Berkeley Laboratory, University of California, Berkeley, California 94720

\section{Abstract}

In an attempt to overcome the limitations and drawbacks of using fresh platelets for transfusion therapy of thrombocytopenic patients, we have performed in vitro experiments on an autologous, semi-artificial alternative to platelet transfusions. Based on our previous studies of the interactions of unactivated and activated platelets with beads coated with peptides of various lengths, all of which contained the arginine-glycineaspartic acid (RGD) cell recognition sequence, the peptide AcCGGRGDF-NH $\mathrm{N}_{2}$ was chosen for covalent coupling to erythrocytes. A heterobifunctional crosslinking reagent $(\boldsymbol{N}$-maleimido6-aminocaproyl ester of 1-hydroxy-2-nitrobenzene-4-sulfonic acid) was used to crosslink via the peptide's free sulfhydryl group and the erythrocyte's surface amino groups. Approximately 0.5-1.5 $\times 10^{6}$ peptide molecules bound per erythrocyte after $\mathbf{2 ~} \mathrm{h}$ of incubation, and most of the peptides appeared to crosslink to glycophorin $\mathbf{A}$. The resulting cells, termed thromboerythrocytes, interacted selectively with activated platelets to form mixed aggregates. Studies with fluid phase RGD peptides and monoclonal antibodies indicated that the RGD peptides on the thromboerythrocytes interacted with the GPIIb/ IIIa receptors on activated platelets. Thromboerythrocytes could also bind to platelets adherent to collagen. There was minimal erythrocyte hemolysis during the formation of thromboerythrocytes and studies of thromboerythrocyte osmotic fragility and cellular deformability showed no significant changes from control erythrocytes. Whereas there is a 20:1 ratio of erythrocytes to platelets in the circulation of normal individuals, the erythrocytes from as little as $50 \mathrm{ml}$ of blood could be transformed into the equivalent of $2 \mathrm{U}$ of platelets by numbers (equivalent to $18 \mathrm{U}$ of platelets by mass), and reinfused into the same individual within several hours. These data encourage us to proceed to in vivo studies to assess the hemostatic efficacy of thromboerythrocytes in thrombocytopenic animals. (J. Clin. Invest. 1992. 89:546-555.) Key words: platelets • erythrocytes • RGD peptides $\bullet$ GPIIb/IIIa receptors

\section{Introduction}

Platelet transfusion is the only effective therapy for the prevention and treatment of hemorrhage due to thrombocytopenia

Parts of this work have been published in abstract form (1990. Circulation. 82:III-2377; and 1991. Thromb. Haemostasis. 65:310).

Address correspondence to Dr. Coller, Division of Hematology, State University of New York at Stony Brook, Stony Brook, NY 11794.

Received for publication $30 \mathrm{July} 1991$ and in revised form 21 October 1991.

J. Clin. Invest.

(c) The American Society for Clinical Investigation, Inc.

0021-9738/92/02/0546/10 \$2.00

Volume 89, February 1992, 546-555
(1). The number of units of platelets transfused each year in the United States has grown rapidly since the widespread introduction of platelet transfusion therapy in the 1960s; in fact, just between 1980 and 1987 the number nearly doubled, reaching in excess of 6 million units per year (2). Despite its enormous success, platelet transfusion therapy has a number of very serious limitations and drawbacks: $(a)$ supplies are often limited due to difficulties in procurement and the relatively short shelf life (5-7 d) (3); (b) there is a risk of transmitting blood-borne pathogens such as the viruses that produce hepatitis and AIDS, especially since multiple units are usually administered with each transfusion $(1) ;(c)$ febrile reactions, presumably due to white blood cell contaminants, are common in patients receiving repeated transfusions (4); and $(d)$ alloimmunization results in patients becoming refractory to random donor platelets, necessitating a switch to single donor platelets matched for HLA antigens, and even HLA-matched platelet transfusions are not universally successful (1).

The availability of an abundant and safe alternative to human platelets would, therefore, be of considerable benefit. It is vital, however, that such an alternative retain the platelet's specificity for forming thrombi at sites of vascular injury, to be certain that indiscriminate thrombus formation does not occur. As a first step in trying to meet these stringent requirements, we have developed an autologous, semi-artificial alternative to platelet transfusion by altering the membrane surface of erythrocytes so that they can interact selectively with activated platelets. In recognition of the dual nature of such a cell, we have named it a "thromboerythrocyte."

A series of observations extending back more than a decade led to this approach. In 1980, one of us (B. Coller) demonstrated that platelets would interact with inert beads coated with fibrinogen and that the interactions were more rapid if the platelets were activated with ADP (5). Subsequent studies by Agam and Livne showed that fixed platelets containing covalently bound fibrinogen can passively participate in platelet aggregation when they are mixed with fresh, unfixed platelets that are stimulated with thrombin, ionophore A23187, or ADP (6-8). Agam and Livne went on to show that erythrocytes coated with fibrinogen by formaldehyde treatment can enter into aggregates with activated platelets in vitro; moreover, when injected in vivo, these erythrocytes shorten the bleeding time of rats made thrombocytopenic by injection of antiplatelet serum (9).

The discovery that the arginine-glycine-aspartic acid (RGD) sequence on fibrinogen is recognized by the platelet GPIIb/IIIa receptor (10) led us to consider covalently attaching an RGD-containing peptide instead of fibrinogen to erythrocytes, since this would avoid the problems associated with purification of human fibrinogen from plasma and the potential for transmission of infectious agents. It was unclear, however, whether erythrocytes coated with RGD-containing peptides 
would interact with platelets, and equally important, whether the interactions would be selective for activated platelets, a prerequisite for diminishing the risks of indiscriminate thrombus formation. In a series of studies on peptides of the general structure (G) ${ }_{n}$-RGDF (where $n$ equals the number of glycine residues) that were covalently attached to polyacrylonitrile beads via their amino termini, we discovered that the length of the peptide profoundly affected the ability of the beads to interact with platelets (11). Thus, with beads coated with peptides with $n=1$, very little interaction occurred between the beads and either unactivated or activated platelets, whereas with $n$ $=9$, strong interactions occurred with both unactivated and activated platelets. When the peptide had $n=3$, the interactions were highly dependent on the state of platelet activation, with platelets treated with $\mathrm{PGE}_{1}$ reacting poorly if at all, and platelets treated with ADP reacting briskly. These studies encouraged us to try to find a peptide and crosslinking procedure that would produce thromboerythrocytes capable of selectively interacting with activated platelets.

\section{Methods}

Peptides. The peptide Ac-CGGRGDF- $\mathrm{NH}_{2}$ was made on an automated peptide synthesizer (model 430A; Applied Biosystems, Inc., Foster City, CA) using t-boc chemistry and a 4-methylbenzhydrylamine resin. In four of the five syntheses, the coupling solvent was dimethylformamide, whereas in the fifth it was $N$-methylpyrrolidone. The protecting groups were $\beta$ benzyl ester for the aspartic acid, tosyl for the arginine, and 4-methylbenzyl for the cysteine. Double couplings were performed with the phenylalanine in three of the syntheses and arginine in all of the syntheses. The amino terminus was acetylated while the peptide was still on the resin by reaction with acetic anhydride. Cleavage of the peptide from the resin was accomplished with anhydrous hydrogen fluoride (HF) in the presence of dimethylsulfide, parathiocresol, and anisole, starting at $-10^{\circ} \mathrm{C}$. After $\mathrm{HF}$ cleavage, the peptide-resin mixture was washed with ether alone (first two syntheses) or ether and dichloromethane (last three syntheses), and then extracted into acetic acid before lyophilization. HPLC analysis (C-8 column, 220 $\times 4.6 \mathrm{~mm}$; model $300 \mathrm{RP}$; Applied Biosystems, Inc.) demonstrated a single dominant peak in each synthesis representing $45-57 \%$ of the total absorbance at $220 \mathrm{~nm}$. For some experiments the peptide was purified by HPLC before use. Fast atom bombardment mass spectrometry (xenon gun parameters: $7 \mathrm{kV}, 1 \mathrm{~mA}, 0.4 \mathrm{~mA}$ ion current; mass spectrometer parameters: acceleration potential $6 \mathrm{kV}$, mass range 132 1,172 , resolution 1,500 , scan speed $10 \mathrm{~s}$ /decade; lyophilized sample transferred to glycerin or thioglycerin matrix) was performed on two of the five peptides and demonstrated that the peptides had the expected mass of $751 \mathrm{D}$.

The peptide concentration for the coupling experiments was determined by titrating the free sulfhydryl groups with 5,5'-dithio-bis-(2-nitrobenzoic acid) (Ellman's reagent; Pierce Chemical Co., Rockford, IL) using cysteine as a standard (12). A radiolabeled peptide was prepared by performing the peptide acetylation reaction $(0.3 \mathrm{mg}$ of resin) with $0.05 \mathrm{mmol}(25 \mathrm{mCi})$ of $\left[{ }^{3} \mathrm{H}\right]$ acetic anhydride (Amersham Corp., Arlington Heights, IL) in a mixture of $4.75 \mathrm{ml}$ dichloromethane and 0.25 $\mathrm{ml}$ diisopropyl ethylamine for $120 \mathrm{~min}$ at $22^{\circ} \mathrm{C}$ with stirring and then adding $0.5 \mathrm{ml}$ ( $5 \mathrm{mmol}$ ) unlabeled acetic anhydride for an additional 5 min. The resin was then allowed to float undisturbed, the fluid was removed, and $5 \mathrm{ml}$ of $10 \%$ acetic anhydride $(\sim 5 \mathrm{mmol})$ in dichloromethane was added to the resin and allowed to react for another $5 \mathrm{~min}$. The resin was filtered and washed first in dichloromethane and then in methanol, and then the peptide was cleaved from the resin with HF in the presence of scavengers. The ${ }^{3} \mathrm{H}$-peptide had a specific activity of 1.3 $\times 10^{11} \mathrm{dpm} / \mathrm{mmol}$ peptide. HPLC analysis demonstrated that $83 \%$ of the radioactivity eluted with the peptide peak.

Preparation of thromboerythrocytes. Our crosslinking strategy was: (a) to join the peptide to the heterobifunctional crosslinking agent $\mathrm{N}$ - maleimido-6-aminocaproyl ester of 1-hydroxy-2-nitrobenzene-4-sulfonic acid (mal-sac-HNSA; Bachem Bioscience, Bubendorf, Switzerland) via a reaction between the free sulfhydryl on the peptide and the crosslinker's maleimide moiety, and then $(b)$ to join the peptide-crosslinker to the erythrocyte via a reaction between the erythrocytes' amino groups and the aminocaproyl ester, resulting in the release of the highly absorbent 1-hydroxy-2-nitrobenzene-4-sulfonic acid dianion from the mal-sac-HNSA (13). To minimize hydrolysis of the ester during the maleimide-sulfhydryl reaction, a $\mathrm{pH}$ of 6.0 was chosen for the first reaction. To speed the reaction between the ester and the erythrocyte amino groups and to insure a physiological $\mathrm{pH}$ for the erythrocytes, a $\mathrm{pH}$ of 7.4 was chosen for the second reaction.

Whole blood was collected by syringe and placed in a polypropylene test tube containing either $0.1 \mathrm{ml} 40 \%$ trisodium citrate or $1.2 \mathrm{ml}$ CPDA-1 anticoagulant ( $89 \mathrm{mM}$ trisodium citrate, $16 \mathrm{mM}$ citric acid, $16 \mathrm{mM} \mathrm{NaH}_{2} \mathrm{PO}_{4}, 160 \mathrm{mM}$ dextrose, $2 \mathrm{mM}$ adenine) so that the final volume was $10 \mathrm{ml}$. The blood was centrifuged at $700 \mathrm{~g}$ for $3.5 \mathrm{~min}$ at $22^{\circ} \mathrm{C}$ for platelet-rich plasma (PRP). ${ }^{\prime}$ After removing the PRP, the blood was recentrifuged at $1,600 \mathrm{~g}$ for $10 \mathrm{~min}$ at $22^{\circ} \mathrm{C}$ and the resulting platelet-poor plasma (PPP) was removed. The buffy coat layer was then removed and discarded, and the erythrocytes were brought up to $50 \mathrm{ml}$ with buffer $\mathrm{A}(140 \mathrm{mM} \mathrm{NaCl}, 5 \mathrm{mM} \mathrm{KCl}, 10 \mathrm{mM}$ glucose, $10 \mathrm{mM} \mathrm{Na}$ phosphate, $\mathrm{pH}$ 7.4). The erythrocytes were then washed three times in buffer $\mathrm{A}$ and resuspended to a hematocrit of $10 \%$ in the same buffer. A 3-ml sample was transferred to a small polypropylene tube and centrifuged at $700 \mathrm{~g}$ for $5 \mathrm{~min}$ at $22^{\circ} \mathrm{C} ; 2.5 \mathrm{ml}$ of the supernatant buffer was then removed, leaving $0.5 \mathrm{ml}$ of a $60 \%$ hematocrit solution $\left(3.3 \times 10^{9}\right.$ erythrocytes). In some experiments, a slightly different buffer was used ( $150 \mathrm{mM} \mathrm{NaCl}, 50 \mathrm{mM}$ Na phosphate, $2 \mathrm{mM} \mathrm{KCl}, 5 \mathrm{mM}$ glucose, $\mathrm{pH}$ 7.4) and the results were the same.

The Ac-CGGRGDF-NH $\mathrm{N}_{2}$ peptide was then dissolved in buffer B $(150 \mathrm{mM} \mathrm{NaCl}, 10 \mathrm{mM}$ Na phosphate, $\mathrm{pH} 6.0)$ at $\sim 2.0 \mathrm{mg} / \mathrm{ml}(2.6$ $\mathrm{mM}$ ) and the solution was readjusted to $\mathrm{pH} 6.0$ with $1 \mathrm{M} \mathrm{NaOH}$. The mal-sac-HNSA was then dissolved at $10 \mathrm{mg} / \mathrm{ml}$ in buffer $B$, and $0.5 \mathrm{ml}$ of the peptide solution $(1.3 \mu \mathrm{mol})$ and $0.05 \mathrm{ml}$ of the mal-sac-HNSA $(1.1 \mu \mathrm{mol})$ were incubated at room temperature for $10 \mathrm{~min}$. The $\mathrm{pH}$ of the solution was then increased to 7.4 with $0.1 \mathrm{M} \mathrm{NaOH}$ and the solution was immediately added to the $0.5 \mathrm{ml}$ of erythrocytes in buffer A. The tube was then gently rocked at $22^{\circ} \mathrm{C}$ for various periods of time, usually up to $2 \mathrm{~h}$, but in some cases $18 \mathrm{~h}$. In other experiments the reaction took place in one step, with the peptide, crosslinker, and erythrocytes incubated together at $\mathrm{pH}$ 7.4-7.5. After the reaction was complete, the thromboerythrocytes were washed three times in buffer A. Thromboerythrocytes were used immediately or stored at $4^{\circ} \mathrm{C}$.

Preliminary studies monitored with Ellman's reagent (to assess the reaction between the maleimide group of mal-sac-HNSA and the sulfhydryl group on the peptide) indicated that when equimolar $(2 \mathrm{mM})$ concentrations of crosslinker and peptide were used at $\mathrm{pH} 6.0$, the maleimide-cysteine reaction was $>95 \%$ complete within $5 \mathrm{~min}$. These preliminary reactions were also monitored at $405 \mathrm{~nm}$ for release of the 1-hydroxy-2-nitrobenzene-4-sulfonic acid dianion from mal-sacHNSA as an indicator of hydrolysis of the amino-reactive moiety on the crosslinker (13). At the end of these experiments, samples were treated with $0.05 \mathrm{vol}$ of $5 \mathrm{~N} \mathrm{NaOH}$, which produces complete release of the dianion (13), to establish the percentage of total dianion that had been released during the reaction. The results indicated that less than $\sim 1 \%$ of the amino-reactive groups on mal-sac-HNSA were hydrolyzed during the 10-min maleimide-cysteine reaction at $\mathrm{pH}$ 6.0.

Quantification of peptide binding. To determine the number of peptide molecules crosslinked to each thromboerythrocyte, the radiolabeled peptide was used in combination with unlabeled peptide. At selected time intervals, thromboerythrocytes were removed from the incubation mixtures, washed three times in buffer A, and then subjected to hypotonic lysis to produce erythrocyte ghosts. This was accomplished by first incubating the erythrocytes with $10 \%$ buffer A (i.e.,

1. Abbreviations used in this paper: HF, hydrogen fluoride; PAS, periodic acid-Schiff; PPP, platelet-poor plasma; PRP, platelet-rich plasma. 
buffer A diluted to $10 \%$ of its original concentration) at $0^{\circ} \mathrm{C}$, then centrifuging at $38,000 \mathrm{~g}$ for $20 \mathrm{~min}$ at $0^{\circ} \mathrm{C}$, removing both the supernatant fluid and the hard red button of cell debris, resuspending the remaining pink ghosts in $1 \%$ cold buffer $A$, and washing twice in cold $1 \%$ buffer A. In some experiments, $0.5 \mathrm{mM}$ EDTA was added to the wash buffer to prevent resealing of erythrocyte ghosts. Finally, the erythrocyte ghosts were solubilized in $0.1-0.4 \mathrm{ml} 1 \%$ SDS, and this solution was added to $6 \mathrm{ml}$ of scintillation fluid (Ultima Gold; Packard Instrument Co., Inc., Meriden, CT) and counted in a liquid scintillation counter (model 1900CA; Packard Instrument Co., Inc.). The number of peptide molecules bound per erythrocyte was then calculated from the radioactivity specifically incorporated into the thromboerythrocytes (i.e., radioactivity associated with the ghosts after reaction with the full thromboerythrocyte incubation mixture [erythrocytes + peptide + crosslinker] minus the radioactivity associated with the ghosts of the nonspecific control [erythrocytes + peptide]). In one experiment, the 10 and $1 \%$ lysis buffers contained the protease inhibitors PMSF ( 1 $\mathrm{mM})$, leupeptin $(0.5 \mathrm{mM})$, and EDTA $(0.5 \mathrm{mM})$. An extra, final wash in the $1 \%$ lysis buffer with just $0.5 \mathrm{mM}$ EDTA was used in this experiment because the ghosts were not easy to resuspend, and solubilization at $37^{\circ} \mathrm{C}$ was achieved with a mixture of $200 \mu \mathrm{l} 10 \%$ SDS $+20 \mu 10.1 \mathrm{M}$ $\mathrm{NaOH}+200 \mu \mathrm{l}$ of a tissue solubilizer (TS-2, $0.5 \mathrm{~N}$; Research Products International Corp., Mount Prospect, IL). The solubilized ghosts were then added to $18 \mathrm{ml}$ of scintillation fluid and counted.

Identification of erythrocyte proteins to which peptides are crosslinked. $1.3 \mu \mathrm{mol}$ pure ${ }^{3} \mathrm{H}$-peptide was reacted for $120 \mathrm{~min}$ with erythrocytes in a two-step reaction as described above. The thromboerythrocytes were then lysed using the cold, hypotonic buffers containing 0.5 mM EDTA, and the resulting ghosts were then dissolved in $100 \mu \mathrm{l} 1.7 \%$ SDS at $15^{\circ} \mathrm{C}$ and frozen at $-80^{\circ} \mathrm{C}$. A platelet-thromboerythrocyte coaggregation assay (see below) on a sample removed before lysis demonstrated that the thromboerythrocytes were active in the assay. Subsequently, a 20- $\mu 1$ sample of the solubilized thromboerythrocytes was thawed, mixed with $20 \mu \mathrm{l}$ of sample mixer and $2 \mu \mathrm{l}$ of 2 -mercaptoethanol, heated to $100^{\circ} \mathrm{C}$ for $3 \mathrm{~min}$, and electrophoresed in a polyacrylamide gel (3\% stacking, $12.5 \%$ resolving gels) according to the method of Laemmli (14). The gel was then stained with the periodic acid-Schiff (PAS) method by fixing overnight in $25 \%$ isopropanol-10\% acetic acid, washing with $10 \%$ acetic acid, incubating with $1 \%$ periodic acid in $3 \%$ acetic acid for $60 \mathrm{~min}$, washing four times with water, reacting with Schiff stain for $60 \mathrm{~min}$ in the dark, and washing three times with $1 \%$ $\mathrm{Na}_{2} \mathrm{~S}_{2} \mathrm{O}_{5}$ in $0.1 \mathrm{M} \mathrm{HCl}$. The gel was then stored overnight in $7 \%$ acetic acid at $4^{\circ} \mathrm{C}$, photographed, stained with Coomassie blue, destained, and rephotographed. Finally, the gel was prepared for fluorography by incubating in a precipitating reagent (solution A) of a fluorography preparation kit (Entensify; New England Nuclear Research Products, Boston, MA) for $30 \mathrm{~min}$ and then incubating in an aqueous fluorescent reagent (solution B) for $30 \mathrm{~min}$. The gel was then dried and placed in a cassette with XAR-5 film (Eastman Kodak Co., Rochester, NY) for $7 \mathrm{~d}$ at $-80^{\circ} \mathrm{C}$.

To more precisely define the proteins to which the peptides crosslinked, intact thromboerythrocytes prepared with ${ }^{3} \mathrm{H}$-peptide were incubated with $150 \mu \mathrm{g} / \mathrm{ml}$ trypsin $(278 \mathrm{U} / \mathrm{mg}$, tos-L-phenylalanine chloromethyl ketone-treated; Worthington Biochemical Corp., Freehold, $\mathrm{NJ}$ ) for $1 \mathrm{~h}$ at $37^{\circ} \mathrm{C}$ in $0.15 \mathrm{M} \mathrm{NaCl}, 0.01 \mathrm{M}$ Tris/ $\mathrm{HCl}, 10 \mathrm{mM}$ glucose, $5 \mathrm{mM} \mathrm{KCl}, \mathrm{pH}$ 8.1. The digested thromboerythrocytes were then centrifuged and the trypsin in the supernatant was inhibited with $1 \mathrm{mM}$ PMSF. The supernatant was then analyzed by SDS-PAGE and fluorography as described above. Preliminary experiments indicated that trypsin treatment of both untreated erythrocytes and nonradioactive thromboerythrocytes releases a fragment of glycophorin A of $M_{\mathrm{r}}$ $\sim 27,000$ which is strongly reactive with the PAS stain and gives a positive immunoblot reaction with a murine monoclonal antibody to glycophorin A (10F7 kindly supplied by Dr. William Bigbee, Lawrence Livermore National Laboratories, Livermore, CA) (15).

Platelet-thromboerythrocyte coaggregation assay. To assess the ability of thromboerythrocytes to enter into developing platelet aggregates, a microtiter assay was developed. PRP was prepared from blood anticoagulated with $0.01 \mathrm{vol} 40 \%$ sodium citrate and adjusted to a platelet count of $3-5 \times 10^{8} / \mathrm{ml}$ with PPP. 50 - or $100-\mu$ laliquots of the PRP were added to microtiter wells and then 5 or $10 \mu l$ of ADP (100 $\mu \mathrm{M}$ stock solution) was added to selected wells, followed by the addition of 5 or $10 \mu \mathrm{l}$ of thromboerythrocytes (10\% hematocrit in buffer A). The microtiter plate was then rotated at $270 \mathrm{rpm}$ at $22^{\circ} \mathrm{C}$ for variable periods of time between 0.5 and $20 \mathrm{~min}$ and the extent of plateletthromboerythrocyte coaggregation was assessed visually on a scale from 0 to 4+ with the aid of a magnifying mirror. To assess the specificity of the reaction, in some experiments the PRP was preincubated with $10 \mu \mathrm{mM}$ EDTA, $300 \mu \mathrm{g} / \mathrm{ml}$ of the peptide RGDF, or $20 \mu \mathrm{g} / \mathrm{ml}$ of an antibody directed against both the GPIIb/IIIa receptor and the $\alpha_{\mathrm{v}} \beta_{3}$ vitronectin receptor that blocks fibrinogen binding to activated platelets $(7 E 3)(16,17)$. Blood smears were made from the samples in some experiments and stained with a standard Wright stain (Hemastain; Geometric Data, Wayne, PA).

To obtain more quantitative data on the coaggregation of thromboerythrocytes with platelets, the assay was adapted to the aggregometer. PRP was prepared from whole blood anticoagulated with ACD-A (8.5:1.5) and gel-filtered over a column of Sepharose 2B (Pharmacia Fine Chemicals, Piscataway, NJ) using a modified Tyrode's buffer (140 $\mathrm{mM} \mathrm{NaCl}, 3 \mathrm{mM} \mathrm{KCl}, 12 \mathrm{mM} \mathrm{NaHCO}, 0.4 \mathrm{mM} \mathrm{NaH}_{2} \mathrm{PO} 4,10 \mathrm{mM}$ Hepes, $2 \mathrm{mM} \mathrm{MgCl}$, $0.2 \%$ BSA, $5 \mathrm{mM}$ glucose, $\mathrm{pH}$ 7.4). Samples consisted of $450 \mu$ l of gel-filtered platelets $+20 \mu$ l of thromboerythrocytes (10\% hematocrit) or control erythrocytes (i.e., erythrocytes incubated with peptide but no crosslinker). Maximal transmission was set with $450 \mu$ l of buffer $+20 \mu$ l of control erythrocytes. Platelets were activated with ADP (4.3 $\mu \mathrm{M}$ final concentration)' or epinephrine $(10 \mu \mathrm{M})$.

Assessment of hemolysis. Hemolysis of erythrocytes during thromboerythrocyte preparation was assayed by the reaction of any free hemoglobin with leucomalachite green (Kodak; $0.1 \%$ p, $p^{\prime}$-benzylidenebis-( $N, N$-dimethylaniline) in $3.3 \mathrm{M}$ acetic acid). The resulting compound was detected by absorbance at $617 \mathrm{~nm}$, a wavelength that is not interfered with by the mal-sac-HNSA dianion. Standards were prepared by lysing known amounts of erythrocytes in deionized water. The assay consisted of $10 \mu \mathrm{l}$ of sample (the supernatant of the reaction mixture after centrifuging to remove intact erythrocytes), $1 \mathrm{ml}$ of leucomalachite green, and $1 \mathrm{ml}$ of $0.1 \% \mathrm{H}_{2} \mathrm{O}_{2}$. After $10 \mathrm{~min}$ the absorbance of each sample was read at $617 \mathrm{nM}$.

Osmotic fragility. Thromboerythrocytes, control erythrocytes, and untreated erythrocytes were added to $\mathrm{NaCl}$ solutions of various concentrations. After $20 \mathrm{~min}$ at $22^{\circ} \mathrm{C}$ the samples were centrifuged and the optical density of the supernatant fluid was assessed at $540 \mathrm{~nm}$. Results were expressed as the percent hemolysis, with $100 \%$ hemolysis defined as the optical density of a sample of erythrocytes added to deionized water.

Binding of thromboerythrocytes to platelets adherent to collagen. The first stage of the assay, involving the adhesion of platelets to purified type 1 rat skin collagen, was performed as described previously, but without radiolabeling the platelets (18). In brief, a sample of gel-filtered platelets $\left(100 \mu \mathrm{l} ; 5.5 \times 10^{8} / \mathrm{ml}\right)$ in the presence of $2 \mathrm{mM} \mathrm{MgCl}_{2}$ was added to microtiter plate wells precoated with collagen and the platelets were allowed to adhere for $1 \mathrm{~h}$ at $22^{\circ} \mathrm{C}$. The wells were then emptied and washed three times with buffer $(0.15 \mathrm{M} \mathrm{NaCl}, 0.01 \mathrm{M}$ Tris/ $\mathrm{HCl}$, $0.05 \% \mathrm{BSA}, 5 \mathrm{mM}$ glucose, $\mathrm{pH}$ 7.4). Control erythrocytes or thromboerythrocytes $(50 \mu \mathrm{l} ; 10 \%$ hematocrit) were then added to the wells in the same buffer, which was now supplemented with $2 \mathrm{mM} \mathrm{MgCl}$. After $60 \mathrm{~min}$ the wells were emptied and washed three times as above. The wells were then visually inspected at $400 \times$ with the aid of a microscope with Nomarski optics. The effect of $20 \mu \mathrm{g} / \mathrm{ml}$ of an antibody to GPIIb/IIIa that blocks fibrinogen binding and platelet aggregation (10E5) (19) and $400 \mu \mathrm{g} / \mathrm{ml}$ of the peptide RGDF on thromboerythrocyte adhesion to platelets was tested by adding these agents to the thromboerythrocytes immediately before the thromboerythrocytes were added to the microtiter wells.

Assessment of thromboerythrocyte volume and surface properties. Laser diffraction ektacytometry was performed on the thromboer- 


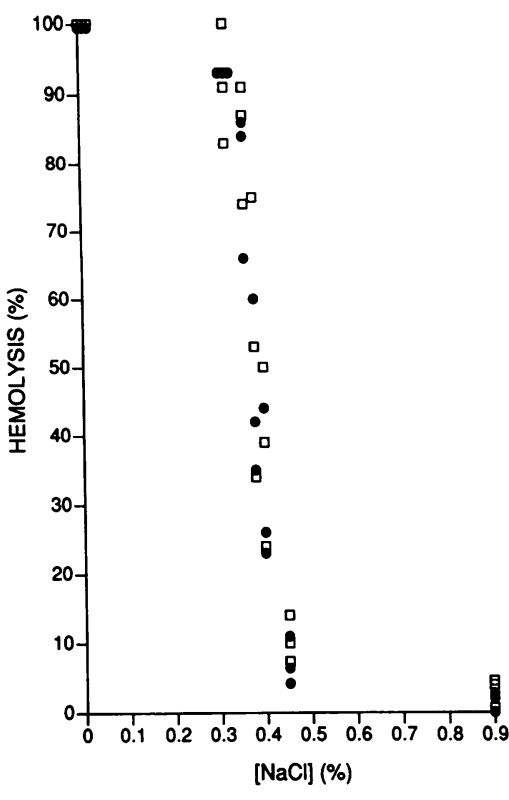

Figure 1. Osmotic fragility of control erythrocytes (๑) and thromboerythrocytes (ם). The lysis of control erythrocytes and thromboerythrocytes was measured after a 20 -min incubation in solutions containing various salt concentrations. The results are expressed in comparison to the hemolysis produced by distilled water, which was defined as $100 \%$.

Data are from three separate experiments.

ythrocytes and control erythrocytes essentially as previously described (20-22) using samples sent by overnight mail on $4^{\circ} \mathrm{C}$ cold packs from Stony Brook, NY to Berkeley, CA. Control erythrocytes or thromboerythrocytes $(20 \mu \mathrm{l}$ of a $\sim 33 \%$ suspension in $0.15 \mathrm{M} \mathrm{NaCl}, 0.01 \mathrm{M}$ Tris/ $\mathrm{HCl}, 5 \mathrm{mM} \mathrm{KCl}, 10 \mathrm{mM}$ glucose, $1 \% \mathrm{BSA}$, pH 7.4 buffer) were added to $3.5 \mathrm{ml}$ of $4 \%$ (wt/vol) polyvinyl pyrrolidone in PBS adjusted to 290 mosmol (viscosity $=22$ centipoise). The samples were then placed in the instrument and the deformability index (a measure of the change in cell shape from circle to ellipse) was measured continuously as the cells were subjected to increasing shear rates $\left(0-1,037 \mathrm{~s}^{-1}\right)$.

\section{Results}

Characterization of thromboerythrocytes. The supernatant fluid after performing the thromboerythrocyte reaction had $0.40 \pm 0.09 \%$ (mean $\pm S D ; n=6$ ) erythrocyte hemolysis compared with $0.13 \pm 0.04 \%(n=6)$ in the control reaction. Studies of osmotic fragility showed only minor differences between thromboerythrocytes and control erythrocytes (Fig. 1 contains data on three separate experiments), and the control erythrocytes did not differ from untreated erythrocytes. Laser ektacytometry demonstrated that the thromboerythrocytes had the same deformability properties as did control erythrocytes and untreated erythrocytes (Fig. 2). Both control erythrocytes and thromboerythrocytes had maximum deformability index values that were within the normal range determined from studies on more than 200 individuals $(0.6 \pm 0.02$; mean $\pm S D)$.

Studies with the ${ }^{3} \mathrm{H}$-peptide. The results of five separate experiments to determine the number of peptide molecules that bound per thromboerythrocyte are shown in Table I. There was a progressive increase in ${ }^{3} \mathrm{H}$-peptides bound per thromboerythrocyte as a function of time, with the reaction slowing down or stopping at the 90-120 min time point. Maximum specific incorporation using $1.3 \mu \mathrm{mol}$ of peptide and $1.1 \mu \mathrm{mol}$ of crosslinker per $3.3 \times 10^{9}$ erythrocytes was $0.5-1.4 \times 10^{6}$ peptide molecules per thromboerythrocyte, representing $\sim 0.3-0.7 \%$ of the added peptide. Nonspecific incorporation was $<3 \%$ of the specific incorporation as judged by control samples in which the crosslinker was omitted. In the three experiments in which the reaction was conducted in a single step, the results were comparable to those achieved using the twostep reaction. In studies where radiolabeled thromboerythrocytes were solubilized in SDS and subjected to polyacrylamide gel electrophoresis, there were three identifiable radioactive bands (Fig. 3). The strongest was at $M_{\mathrm{r}} 87,000$, corresponding to the major PAS-staining band (PAS-1) (23). The second was at $M_{\mathrm{r}} 42,000$ and corresponded to the second PAS-positive band (PAS-2), and the third was a weak band at $M_{\mathrm{r}} 22,000$ corresponding to the third PAS-positive band (PAS-3). The PAS-1 and PAS-2 bands are thought to be composed primarily of glycophorin A dimers and monomers, respectively (23). We therefore assessed the effects of trypsin treatment of ${ }^{3} \mathrm{H}$-thromboerythrocytes since this enzyme cleaves fragments of glycophorin A from the erythrocyte surface (24). We identified a $\sim 27,000-M_{\mathrm{r}}$ fragment that we judged to be derived from glycophorin A based on its apparent molecular weight, strong reac-

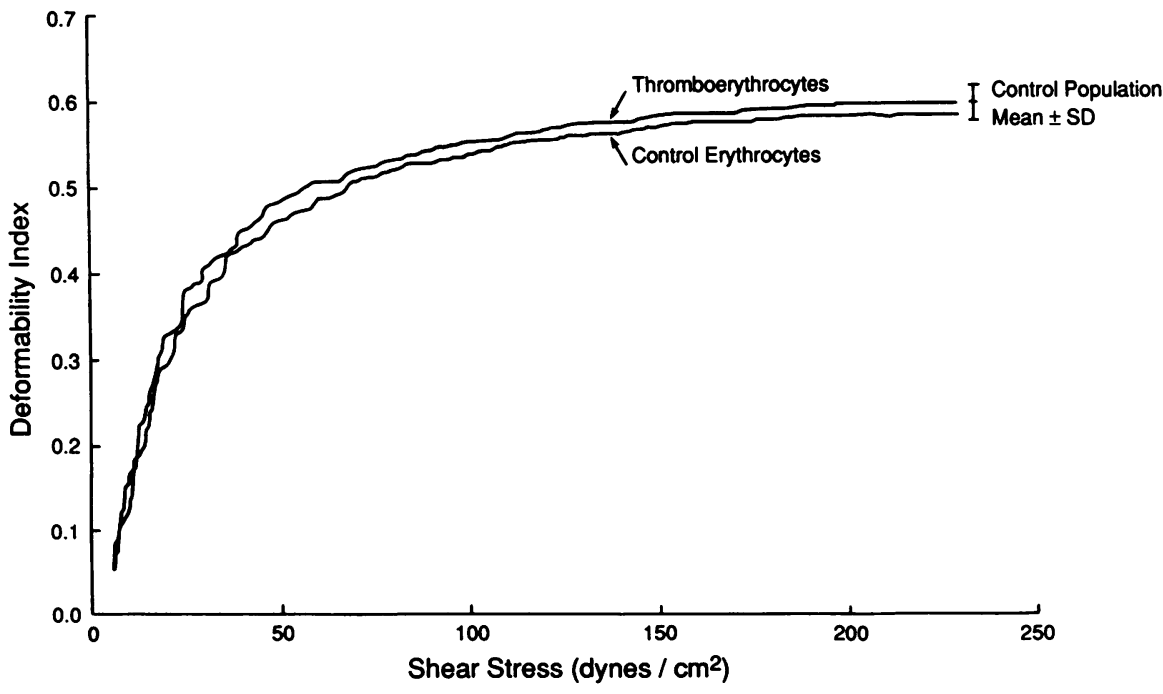

Figure 2. Ektacytometer analysis of thromboerythrocytes and control erythrocytes.

Thromboerythrocytes were prepared as described, with samples removed after 15,30 60 , and $120 \mathrm{~min}$ of incubation. The thromboerythrocytes were then washed in $0.15 \mathrm{M} \mathrm{NaCl}, 10 \mathrm{mM}$ Tris/ $\mathrm{HCl}, 5 \mathrm{mM}$ $\mathrm{KCl}, 10 \mathrm{mM}$ glucose, $1 \% \mathrm{BSA}, \mathrm{pH} 7.4$, and resuspended to a hematocrit of $\sim 33 \%$. Three different erythrocyte controls were prepared: (a) erythrocytes that were just washed in the above buffer, $(b)$ erythrocytes incubated with peptide, but no mal-sacHNSA, and $(c)$ erythrocytes incubated with mal-sac-HNSA, but no peptide. The deformability index of each sample was measured as a function of shear rate in an isotonic medium of 22 centipoise viscosity. All of the thromboerythrocyte samples and control samples gave virtually superimposable curves and so for simplicity only the washed erythrocyte control and the 120-min thromboerythrocyte sample are shown. The plateau deformability index (mean \pm SD) of $>200$ normal samples is also shown, indicating that all of the samples tested were within this normal range. 
Table I. Binding of ${ }^{3} \mathrm{H}-\mathrm{CGGRGDF}$ Peptide to Erythrocytes

\begin{tabular}{|c|c|c|c|c|c|c|c|}
\hline \multirow[b]{2}{*}{ Experiment } & \multirow[b]{2}{*}{$\begin{array}{c}1 \text { step or } \\
2 \text { step }\end{array}$} & \multirow[b]{2}{*}{${ }^{3} \mathrm{H}$-peptide* } & \multirow[b]{2}{*}{ Mal-sac-HNSA* } & \multicolumn{4}{|c|}{ Time (min) } \\
\hline & & & & 30 & 60 & 90 & 120 \\
\hline & & $\mu \mathrm{mol}$ & $\mu \mathrm{mol}$ & & & & \\
\hline 1 & 1 & 0.9 & 1.1 & & & & 570,000 \\
\hline 2 & 1 & 1.3 & 1.1 & 780,000 & $1,100,000$ & $1,400,000$ & $1,400,000$ \\
\hline \multirow[t]{3}{*}{3} & 1 & 1.3 & 1.1 & & 750,000 & & \\
\hline & 2 & 0.6 & 0.55 & & 480,000 & 570,000 & \\
\hline & 2 & 1.3 & 1.1 & 540,000 & 750,000 & 870,000 & $1,100,000$ \\
\hline 4 & 2 & 1.3 & 1.1 & & & & $1,000,000$ \\
\hline 5 & 2 & 1.3 & 1.1 & & & & 500,000 \\
\hline
\end{tabular}

* The number of $\mu \mathrm{mol}$ of the ${ }^{3} \mathrm{H}-\mathrm{CGGRGDF}$ peptide and the crosslinking reagent (mal-sac-HNSA) used in the reactions are indicated. Each reaction mixture contained $\sim 3.3 . \times 10^{9}$ erythrocytes.

tion with the PAS stain, and reaction with a monoclonal antibody to glycophorin (15). When subjected to fluorography, this band was radioactive, confirming the crosslinking to glycophorin A.

Platelet-thromboerythrocyte interactions. In more than 20 separate experiments, thromboerythrocytes prepared by incubating the peptide crosslinker with erythrocytes for $120 \mathrm{~min}$ gave a positive response in the platelet-thromboerythrocyte coaggregation assay using ADP; epinephrine and thrombin were tested in a smaller number of experiments and also found to be effective in stimulating platelet-thromboerythrocyte interactions, visible as macroscopic, red coaggregates (Fig. 4). Microscopic examination of stained smears confirmed the intimate association between platelets and thromboerythrocytes (Fig. 5), with the platelet aggregates acting as bridges between thromboerythrocytes. In contrast, the thromboerythrocytes did not interact with platelets when no agonist was added, demonstrating the selectivity of the thromboerythrocytes for activated platelets. Control erythrocytes, which had been reacted with the peptide but not the crosslinker, did not interact with either unactivated or activated platelets (Fig. 4). When the platelets in these samples were activated, pure platelet aggre-

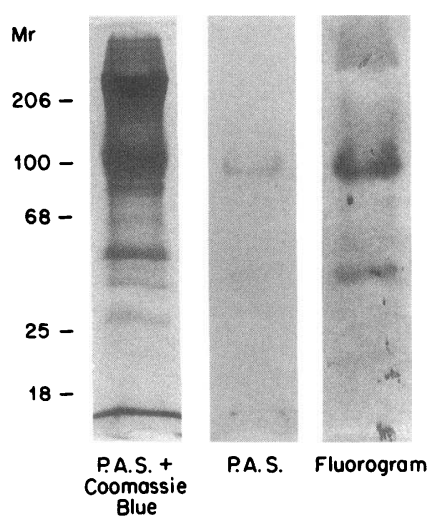

Figure 3. Analysis of thromboerythrocyte membrane proteins involved in peptide crosslinking. After crosslinking the ${ }^{3} \mathrm{H}$-peptide to erythrocytes, the cells were washed and lysed. The thromboerythrocyte ghosts were then solubilized in SDS and electrophoresed in a $12.5 \%$ polyacrylamide gel. The gel was sequentially stained with the PAS technique, photographed, stained with Coomassie blue, photographed, and then prepared for fluorography by reactions with precipitating

and aqueous fluorescent solutions. The gel was subsequently dried and placed in a cassette with $\mathrm{x}$-ray film at $-80^{\circ} \mathrm{C}$ for $7 \mathrm{~d}$. The PAS stain revealed three major bands of $M_{\mathrm{r}} 87,000,42,000$, and 22,000 , which corresponded to the radioactive bands identified by fluorography. gates could be identified microscopically (Fig. 5); macroscopically these appeared as small white clumps (Fig. 4). In time course experiments, crosslinking incubation times as short as 15 min were found sufficient to produce thromboerythrocytes that gave positive reactions in this assay, although the reactions tended to be less strong.

To exclude any confounding effects of the citrate anticoagulant used in these studies, the assay was also performed with PRP anticoagulated with heparin $(4 \mathrm{U} / \mathrm{ml})$ or hirudin $(10 \mathrm{U} /$ $\mathrm{ml}$; Sigma Chemical Co., St. Louis, MO) and similar results were obtained, although as expected, thrombin-induced activation did not occur with these anticoagulants. It is important to note that since these assays contain normal plasma, fibrinogen is available for binding to activated GPIIb/IIIa receptors; thus, the thromboerythrocytes were able to compete effectively with fibrinogen for the GPIIb/IIIa receptors.

Several inhibitors were used to assess whether the thromboerythrocytes were actually binding to the RGD binding site on the activated platelets' GPIIb/IIIa receptors. In fact, the coaggregation was inhibited by a fluid-phase RGD peptide, a monoclonal antibody to GPIIb/IIIa and the $\alpha_{\mathrm{v}} \beta_{3}$ vitronectin receptor that blocks both the binding of fibrinogen to platelets and the interactions between RGD-coated beads and platelets $(11,16,17)$, and EDTA, a strong divalent cation chelator that inhibits the interactions of all ligands with integrin receptors (Fig. 4).

To obtain more quantitative data, an assay was developed using gel-filtered platelets and thromboerythrocytes in an aggregometer. Fig. 6 depicts the results of an experiment demonstrating that thromboerythrocytes, but not control erythrocytes, interact with ADP-activated platelets. The thromboerythrocytes did not interact with unactivated platelets despite the stirring and $37^{\circ} \mathrm{C}$ temperature. $10 \mathrm{E} 5$, a monoclonal antibody to GPIIb/IIIa that blocks the binding of fibrinogen to platelets and partially blocks the interaction of platelets with RGD-coated beads $(11,19)$, inhibited the interaction between platelets and thromboerythrocytes. In this assay, plasma proteins were removed in the gel-filtration step and thus there was little or no exogenous fibrinogen to compete with the thromboerythrocytes for binding to the activated platelets.

Binding of thromboerythrocytes to platelets adherent to collagen. Hemostasis in vivo is thought to be initiated by adhesion of platelets to subendothelial proteins, in particular collagen, 


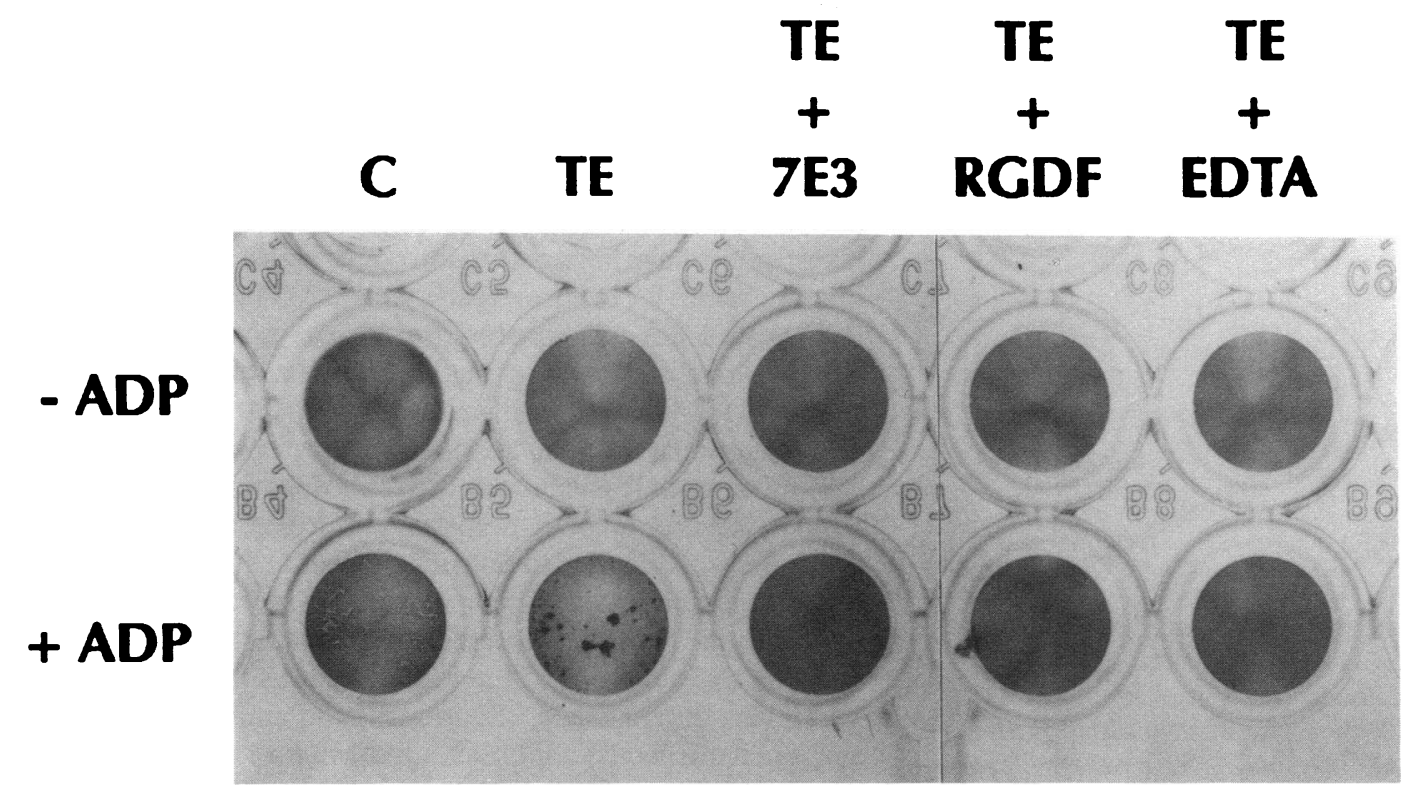

Figure 4. Platelet-thromboerythrocyte coaggregation assay. Thromboerythrocytes and control erythrocytes were prepared as described in the text and adjusted to a $10 \%$ hematocrit. Citrated PRP was prepared $(\sim 500,000$ platelets $/ \mu \mathrm{l})$ and incubated with antibody 7E3 (anti-GPIIb/IIIa + anti$\alpha_{v} \beta_{3}$ vitronectin receptor; $40 \mu \mathrm{g} / \mathrm{ml}$ final concentration), EDTA (10 mM), RGDF $(300 \mu \mathrm{g} / \mathrm{ml})$, or buffer $(0.15 \mathrm{M} \mathrm{NaCl}, 0.01$ $\mathrm{M}$ Tris/ $\mathrm{HCl}, 0.05 \% \mathrm{Na}$ azide, $\mathrm{pH} \mathrm{7.4)} \mathrm{for} 30 \mathrm{~min}$ at $22^{\circ} \mathrm{C}$. The assay was performed by adding 50 $\mu l$ of PRP to microtiter wells, followed by $10 \mu \mathrm{l}$ of ADP to selected wells, and finally $5 \mu \mathrm{l}$ of the thromboerythrocytes. The microtiter plate was then rotated at $270 \mathrm{rpm}$ at $22^{\circ} \mathrm{C}$ for $\sim 6$ min and then the plate was photographed. Note the absence of platelet aggregation or platelet-erythrocyte coaggregation in the samples without ADP. With ADP treatment, the thromboerythrocytes enter into aggregates with the platelets giving mixed aggregates. Careful inspection of the sample of control erythrocytes with ADP stimulation shows small white aggregates of platelets, indicating that platelet activation and aggregation occurred, but the control erythrocytes did not enter into the aggregates.

when blood vessels are damaged (18). Platelets then aggregate on top of the adherent platelets, presumably as a result of the GPIIb/IIIa receptors on the lumenal surface of the adherent platelets undergoing the transformation that allows them to

\section{Thromboerythrocytes}
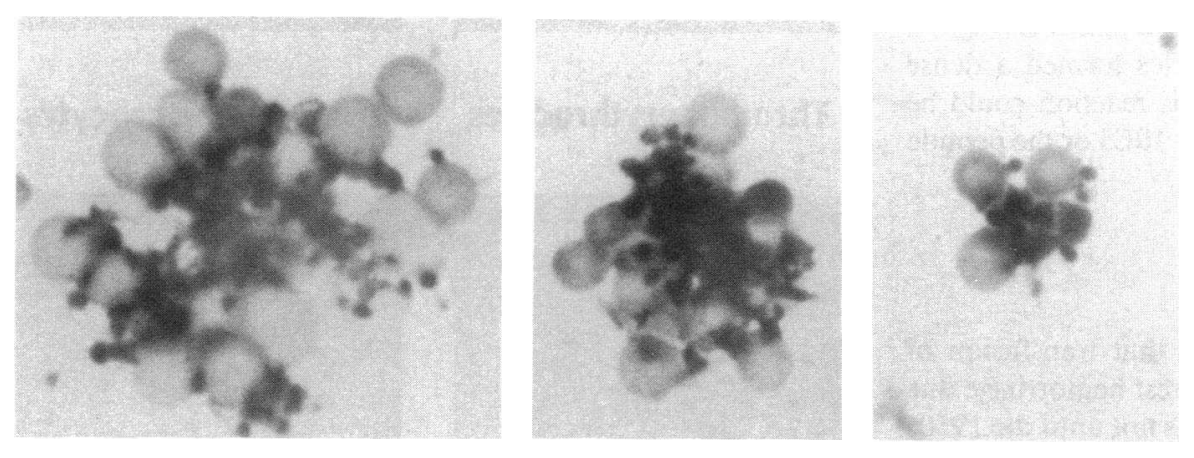

\section{Control Erythrocytes}

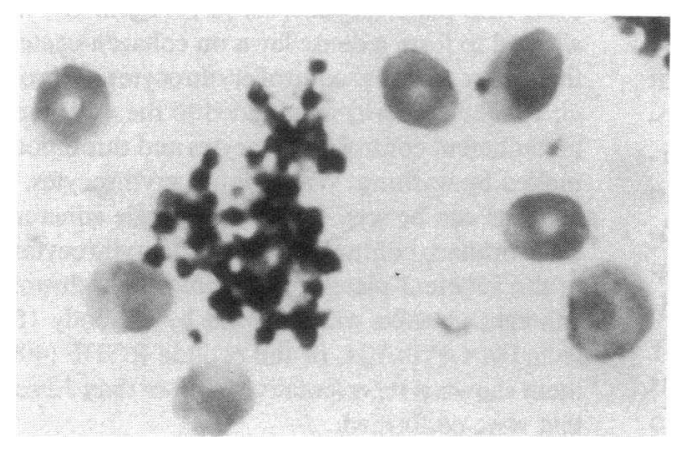

bind adhesive glycoproteins such as fibrinogen and von Willebrand factor with high affinity (10). We therefore tested the ability of thromboerythrocytes to bind to platelets that had adhered to collagen. As in our previous studies (18), a dense 


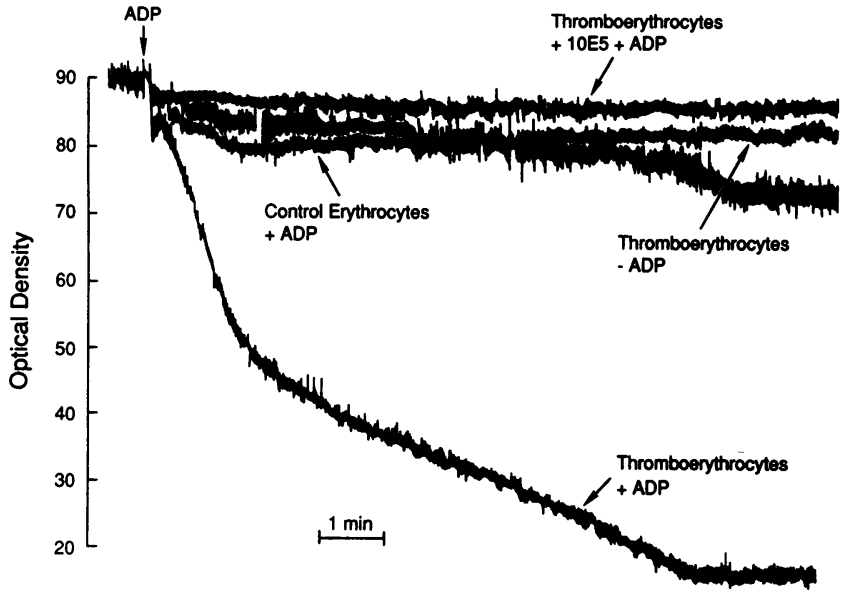

Figure 6. Interactions of control erythrocytes and thromboerythrocytes with gel-filtered platelets. Gel-filtered platelets $(450 \mu \mathrm{l} ; 340,000$ ) $\mu$ l) prepared as described in Methods, and control erythrocytes or thromboerythrocytes $(20 \mu \mathrm{l} ; 10 \%$ hematocrit) were stirred in an aggregometer cuvette and then ADP ( $4.3 \mu \mathrm{M}$ final concentration) was added. In this assay, the erythrocytes contribute significantly to the optical density. Control erythrocytes do not enter into platelet aggregates and so there is only a slight decrease in optical density in this sample. In contrast, thromboerythrocytes do interact with the ADPactivated platelets, resulting in a dramatic decrease in optical density. The thromboerythrocytes do not, however, interact with unactivated platelets despite stirring at $37^{\circ} \mathrm{C}$. Finally, preincubating the platelets with antibody 10E5, which reacts with GPIIb/IIIa, blocks the platelet-platelet and platelet-thromboerythrocyte interactions. A mixture of gel-filtration buffer $(450 \mu \mathrm{l})$ and control erythrocytes $(20 \mu \mathrm{l})$ was used to establish the full scale deflection.

lawn of platelets adhered to the collagen in the presence of 2 $\mathrm{mM} \mathrm{MgCl} 2$. When control erythrocytes were then added, virtually none of the erythrocytes bound to the platelets (Fig. 7). In sharp contrast, the thromboerythrocytes formed a dense lawn on top of the platelet lawn and this reaction could be virtually completely inhibited by antibody $10 \mathrm{E} 5$ or the peptide RGDF (Fig. 7).

\section{Discussion}

In 1910 Duke provided data suggesting that transfusion of whole blood containing platelets could arrest hemorrhage due to thrombocytopenia (25). However, it was not until the 1950s that unequivocal data on the efficacy of platelet transfusions were obtained in animals made thrombocytopenic by treatment with total body irradiation (26). The difficulties in platelet procurement and storage led investigators to seek alternatives to fresh platelets soon thereafter. Studies performed with lyophilized platelets and disintegrated platelets indicated that these products failed to arrest bleeding (26-28). When phospholipids were found capable of substituting for platelets in accelerating coagulation reactions, the cephalin fraction of soy bean phosphatides was investigated as a platelet substitute in thrombocytopenic children (29). Although a preliminary report suggested clinical improvement in some patients (29), animal studies did not identify a benefit and this approach was eventually abandoned (30). Cryopreservation of autologous platelets has been successfully utilized in patients with problems related to alloimmunization and isoimmunization (31), but the platelet yield is less than with fresh platelets, and the technique is limited by the need for extra processing and the availability of storage space (3).

Improved understanding of platelet physiology has led to additional approaches to obtain a platelet substitute. Several investigators have been able to introduce platelet glycoproteins into liposomes for in vitro experiments (32-34). More recently, Ryback and Renzulli incorporated a deoxycholate extract of platelet membranes containing 15 proteins, including GPIb, GPIIb/IIIa, and GPIV into small (50-200 nm) unilamellar liposomes prepared from either sphingomyelin:phosphatidylcholine:monosialylganglioside or egg phosphatide (35). Intraarterial injections of both preparations decreased bleeding in thrombocytopenic rats to the same extent as human platelets did, but neither produced complete normalization of the bleeding time. Intravenous injections were also able to decrease the bleeding time, but not to the same extent as the intraarterial injections. Interestingly, liposomes containing GPIIb/IIIa alone were ineffective (35). This approach may provide important mechanistic information, but as a therapeutic intervention it potentially suffers from the generic problems of liposomes,
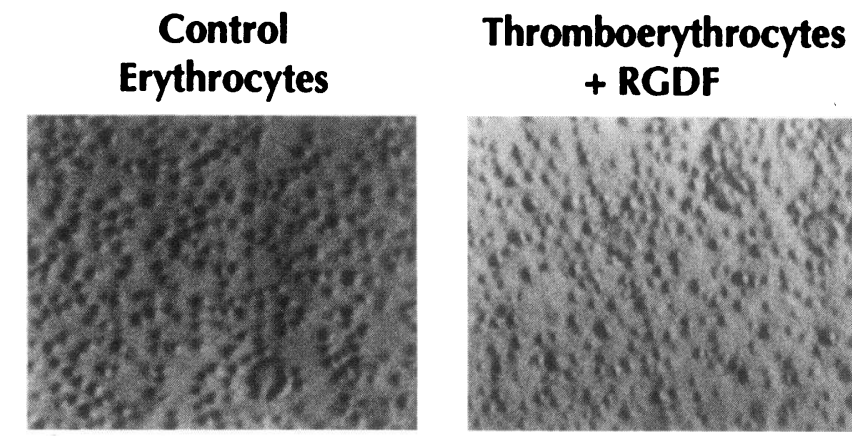

\section{Thromboerythrocytes}
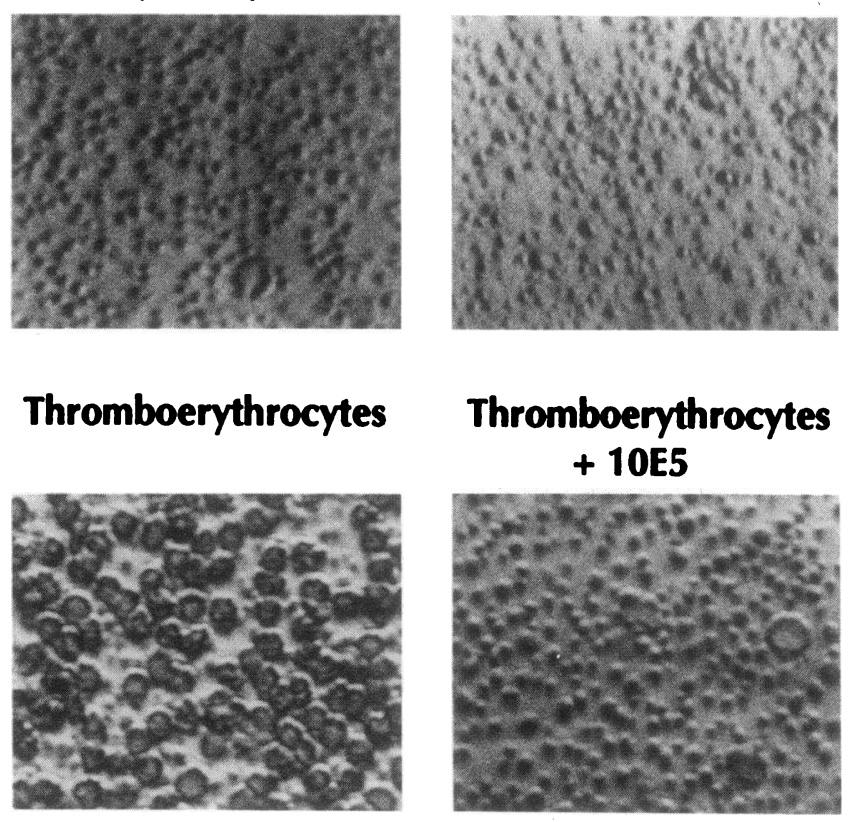
$+10 \mathrm{E} 5$

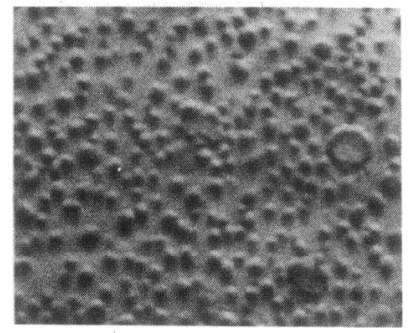

Figure 7. Interactions of control erythrocytes and thromboerythrocytes with platelets adherent to collagen. Gel-filtered platelets were allowed to form a dense lawn on collagen-coated microtiter wells and then, after washing, control erythrocytes or thromboerythrocytes ( 50 $\mu \mathrm{l} ; 10 \%$ hematocrit) were added to the wells for $1 \mathrm{~h}$ at $22^{\circ} \mathrm{C}$. Finally, nonadherent control erythrocytes and thromboerythrocytes were removed by washing. With control erythrocytes, the dense lawn of platelets can be seen with only a single adherent erythrocyte in the field. In sharp contrast, the thromboerythrocytes bound extensively to the adherent platelets. The binding of thromboerythrocytes to the adherent platelets was inhibited by antibody $10 \mathrm{E} 5(20 \mu \mathrm{g} / \mathrm{ml})$, directed at GPIIb/IIIa, or the peptide RGDF $(400 \mu \mathrm{g} / \mathrm{ml})$. The experiment shown is representative of more than 12 separate experiments that were performed. 
including the possibility of short in vivo survival and potential blockade of the reticuloendothelial system (30). Moreover, since platelets remain the starting material, problems of platelet procurement and the risks of transmitting infectious diseases may not be eliminated. Finally, if whole platelet extracts are required, immunogenicity may limit the opportunity for repeat therapy because platelets have class I HLA antigens (36) and some platelet glycoproteins are polymorphic (37-39).

Agam and Livne took a novel approach that was based on their observations that passive, fixed platelets coated with fibrinogen could function to augment platelet aggregation of native, fresh platelets (6-8). They concluded that the activated platelets had to undergo the release reaction and expose thrombospondin on their surface in order for the interactions to occur, with the final interaction between the fibrinogen on the fixed platelets and the thrombospondin on the activated platelets (6-8). This suggests that the fixation process alters the fibrinogen so that it cannot interact directly with GPIIb/IIIa, but leaves intact portions of the fibrinogen molecule that can interact with thrombospondin. Using erythrocytes coated with fibrinogen by a formaldehyde crosslinking method, they went on to show selective in vitro reactivity with activated platelets (9). In addition, they demonstrated that the injection of fibrinogencoated erythrocytes could decrease the bleeding time in rats made acutely thrombocytopenic (9). The major limitation of this approach is that it relies on the purification of fibrinogen from plasma, and thus has the risk of transmitting blood-borne disease; recombinant fibrinogen, if available in sufficient quantities, might overcome this problem (40). Formaldehyde is a cytotoxic agent that may have carcinogenic potential (41) and so it may not be the most desirable crosslinking reagent for in vivo use.

In an attempt to improve on these previous approaches, we have covalently attached the peptide Ac-CGGRGDF-NH $\mathrm{N}_{2}$ to erythrocytes via their surface amino groups with the aid of a heterobifunctional crosslinking reagent. Approximately 0.5$1.5 \times 10^{6}$ peptide molecules are crosslinked per erythrocyte after $120 \mathrm{~min}$. The peptide appears to be selectively crosslinked to glycoproteins that are present in the PAS-1, PAS-2, and PAS-3 regions, making it most likely that it is crosslinked to glycophorin A (whose dimeric form is largely responsible for PAS-1 and whose monomeric form is largely responsible for PAS-2), and the related glycoprotein, glycophorin B (which is largely responsible for PAS-3) (23). Crosslinking to glycophorin A was confirmed by showing radioactivity in a trypsin fragment of glycophorin A. It is interesting that there are an estimated $0.2-1.0 \times 10^{6}$ glycophorin A molecules per erythrocyte and $\sim 0.25 \times 10^{6}$ glycophorin B molecules per erythrocyte (42), raising the possibility that there is $1: 1$ stoichiometry between the number of crosslinked peptide molecules and the number of glycophorin A + glycophorin B molecules.

Thromboerythrocytes were analyzed in several ways. The crosslinking reaction itself produced only slightly more hemolysis than simply washing the erythrocytes. In addition, there were only minimal changes in osmotic fragility. Laser diffraction ektacytometry, a technique that quantitates cellular deformability and is sensitive to changes in the erythrocyte membrane and the hydration state of the cytoplasm of the erythrocyte, has been a useful tool in analyzing erythrocytes altered in vitro and erythrocytes from patients with a variety of disorders (20-22). Using this technique, reduced cellular deformability has been documented in many disorders associated with short- ened in vivo erythrocyte survival (21). It is notable, therefore, that the deformability of thromboerythrocytes was indistinguishable from untreated erythrocytes, suggesting that it is unlikely that these cells will be sequestered in the reticuloendothelial system as a consequence of mechanical alterations in their surface properties.

Thromboerythrocytes are able to selectively interact with platelets activated with ADP, epinephrine, or thrombin to produce large aggregates containing mixtures of platelets and erythrocytes. Studies with monoclonal antibodies to GPIIb/IIIa and fluid-phase RGD peptides indicate that the RGD peptides on the erythrocytes bind to the activated GPIIb/IIIa receptors on the platelets. The interactions occur even in the presence of normal amounts of plasma fibrinogen, indicating that the thromboerythrocytes can compete effectively with fibrinogen for binding to activated GPIIb/IIIa receptors. In addition, the interactions are not dependent upon the low calcium environment found in citrated PRP since platelets in PRP prepared from blood anticoagulated with either heparin or hirudin are also able to interact with the thromboerythrocytes.

To simulate better the likely in vivo situation at a site of vascular injury, where platelets first adhere to adhesive proteins in the blood vessel wall, we also tested the ability of the thromboerythrocytes to bind to platelets that had adhered to collagen. The thromboerythrocytes, but not control erythrocytes, bound readily to the adherent platelets, and studies with a monoclonal antibody to GPIIb/IIIa and RGD peptides again supported a mechanism involving the interaction of the RGD peptides with the activated GPIIb/IIIa receptors.

These in vitro studies encourage us to continue to pursue the thromboerythrocyte as a potential alternative to fresh platelets. Since there are 20 times as many erythrocytes as platelets in the circulation of normal individuals, conversion of the erythrocytes contained in $50 \mathrm{ml}$ of blood into thromboerythrocytes would produce as many thromboerythrocytes as there are platelets in 1 liter of blood, or approximately 2 conventional units of platelets by number. Moreover, since erythrocytes are nine times as large as platelets, the $50 \mathrm{ml}$ of blood would yield the equivalent of 18 conventional units of platelets by mass. The technique of erythrocyte washing is already standard practice in blood banks and the crosslinking reaction can be carried out within 1-2 hours, depending upon the density of peptides selected. Thus, it is theoretically possible that thromboerythrocytes could function as an autologous, semi-artificial platelet alternative.

There are, however, several crucial issues that need to be investigated further. It remains to be established whether the in vitro interactions we have demonstrated between platelets and thromboerythrocytes will translate into improved hemostasis in vivo. Since the hemostatic effectiveness of thromboerythrocytes relies, in part, on the function of residual platelets, the minimum number of residual platelets required for a positive effect remains to be established. The in vivo survival of thromboerythrocytes also needs to be assessed since this will have an impact on the efficacy of the therapy. The ektacytometry data demonstrated that the rheological properties of thromboerythrocytes are indistinguishable from control erythrocytes, and so these rheologic properties of thromboerythrocytes are compatible with normal survival. It is still possible, however, that the alteration of the erythrocyte surface may result in premature removal. One potentially relevant observation is that modification of erythrocyte amino groups with $N$-hydroxysuccinimido- 
biotin, a reagent with reactivity similar to that of the mal-sacHNSA crosslinker used in these studies, did not shorten erythrocyte survival at all when 27,000 molecules were bound per erythrocyte; even at 126,000 biotin molecules per erythrocyte, $>50 \%$ of the erythrocytes survived in excess of $10 \mathrm{~d}$ (43). At present, the optimal number of peptide molecules per erythrocyte is unknown and this will have to be determined before survival data can be obtained. The immunogenicity of the thromboerythrocytes is another important issue, since the development of antibodies to thromboerythrocytes may limit the efficacy of repeated doses. Since the RGD sequence plays such an important role in human biology (10) and is so well conserved in other species, it may well be poorly immunogenic. The crosslinking reagent, mal-sac-HNSA, was designed to minimize its immunogenicity (13), and studies using mal-sacHNSA to couple peptides to carrier proteins for the purpose of producing antibodies have demonstrated that a strong immune reaction to the peptide can be elicited without developing antibodies to the crosslinker (13). It is still possible, however, that the binding of the peptide may alter the immunogenicity of glycophorin and lead to an immune response.

In addition to their functions in platelet adhesion and aggregation, platelets make other contributions to enhancing hemostasis and so it is appropriate to question whether thromboerythrocytes might also serve to enhance the hemostatic response. One of the functions platelets serve is to act as a surface on which coagulation reactions take place (44). Both unique platelet receptors and the platelets' nonspecific phospholipid membrane have been implicated in this function and the contribution of each is unclear (44). The erythrocyte membrane can also serve to accelerate coagulation reactions under certain circumstances and so it is possible that thromboerythrocytes may also be able to facilitate thrombin formation (45). The recent discovery that erythrocytes can enhance platelet activation via cooperative biochemical interactions with platelets involving eicosanoid metabolism (46) provides another potential mechanism by which thromboerythrocytes may enhance the function of residual platelets. Platelets release ADP from their dense granules when stimulated, leading to ADP-induced platelet activation; erythrocytes are rich in ADP and so it is possible that ADP may leak from thromboerythrocytes that become enmeshed in hemostatic plugs. Finally, the identification of nitric oxide produced by cells in the blood vessel wall as a potent inhibitor of platelet activation suggests another potential mechanism by which thromboerythrocytes may enhance platelet function since free hemoglobin and hemoglobin in erythrocytes have been demonstrated to neutralize the effect of nitric oxide (47).

\section{Acknowledgments}

We would like to thank Drs. Dwight Martin, Murugavel Muthusamy, and Allen Meek of the State University of New York at Stony Brook for their contributions to these studies, Robert Rieger, Department of Pharmacology, State University of New York at Stony Brook, for assistance with the fast atom bombardment mass spectra, the Center for Analysis and Synthesis of Macromolecules at Stony Brook for peptide synthesis, and Shirley Murray for outstanding secretarial assistance.

This work was supported by grant 19278 from the National Heart, Lung, and Blood Institute, grant 26263 from the National Institute of Digestive and Kidney Diseases, and a grant from the Center for Biotech- nology, SUNY at Stony Brook, which is sponsored by the New York State Science and Technology Foundation.

\section{References}

1. Heyman, M. R., and C. A. Schiffer. 1991. Platelet transfusion to patients receiving chemotherapy. In Principles of Transfusion Medicine. Williams \& Wilkins Co., Baltimore. 223-231.

2. Surgenor, D. MacN., E. Wallace, S. H. S. Hao, and R. H. Chapman. 1990. Collection and transfusion of blood in the United States, 1982-1988. N. Engl. J. Med. 322:1646-1651.

3. Murphy, S. 1991. Preparation and storage of platelet concentrates. In Principles of Transfusion Medicine. Williams \& Wilkens Co., Baltimore. 205-213.

4. Snyder, E. L., and G. Stack. 1991. Febrile and nonimmune transfusion reactions. In Principles of Transfusion Medicine. Williams \& Wilkins Co., Baltimore. 641-648.

5. Coller, B. S. 1980. Interaction of normal, thrombasthenic, and BernardSoulier platelets with immobilized fibrinogen: defective platelet-fibrinogen interaction in thrombasthenia. Blood. 55:169-178.

6. Agam, G., and A. Livne. 1983. Passive participation of fixed platelets in aggregation facilitated by covalently bound fibrinogen. Blood. 61:186-191.

7. Agam, G., and A. Livne. 1984. Platelet-platelet recognition during aggregation: distinct mechanism determined by the release reaction. Thromb. Haemostasis. 51:145-149.

8. Agam, G., and A. Livne. 1988. Resolution and reconstitution of interplatelet recognition during aggregation. Thromb. Haemostasis. 59:504-506.

9. Agam, G., and A. A. Livne. 1991. Erythrocytes with covalently-bound fibrinogen as a cellular replacement for the treatment of thrombocytopenia. Eur. J. Clin. Invest. In press.

10. Plow, E. F., and M. H. Ginsberg. Cellular adhesion: GPIIb-IIIa as a prototypic adhesion receptor. Prog. Hemostasis Thromb. 10:117-156.

11. Beer, J. H., K. T. Springer, and B. S. Coller. 1992. Immobilized Arg-GlyAsp (RGD) peptides of varying lengths as structural probes of the platelet glycoprotein IIb/IIIa receptor. Blood. 79. In press.

12. Ellman, G. L. 1959. Tissue sulfhydryl groups. Arch. Biochem. Biophys 82:70-77.

13. Aldwin, L., and D. E. Nitecki. 1987. A water-soluble, monitorable peptide and protein crosslinking agent. Anal. Biochem. 164:494-501.

14. Laemmli, U. K. 1970. Cleavage of structural proteins during the assembly of the head of the bacteriophage $\mathrm{T}_{4}$. Nature (Lond.). 227:680-682.

15. Bigbee, W. L., R. G. Langlois, M. Vanderlaan, and R. H. Jensen. 1984. Binding specificities of eight monoclonal antibodies to human glycophorin A: studies with $M^{\mathrm{c}} M$, and $M^{\mathrm{k}} \mathrm{En}(\mathrm{UK})$ variant human erythrocytes and $\mathrm{M}$ - and $\mathrm{MN}^{\mathrm{v}}$ type chimpanzee erythrocytes. J. Immunol. 133:3149-3155.

16. Coller, B. S. 1985. A new murine monoclonal antibody reports an activation-dependent change in the conformation and/or microenvironment of the platelet GPIIb/IIIa complex. J. Clin. Invest. 76:101-108.

17. Coller, B. S., D. A. Cheresh, E. Asch, and U. Seligsohn. 1991. Platelet vitronectin receptor expression differentiates Iraqi-Jewish from Arab patients with Glanzmann thrombasthenia in Israel. Blood. 77:75-83.

18. Coller, B. S., J. H. Beer, L. E. Scudder, and M. H. Steinberg. 1989. Collagen-platelet interactions: evidence for a direct interaction of collagen with platelet GPIIb/IIla mediated by adhesive proteins. Blood. 74:182-192.

19. Coller, B. S., E. I. Peerschke, L. E. Scudder, and C. A. Sullivan. 1983. A murine monoclonal antibody that completely blocks the binding of fibrinogen to platelets produces a thrombasthenic-like state in normal platelets and binds to glycoproteins IIb and/or IIla. J. Clin. Invest. 72:325-338.

20. Mohandas, N., M. R. Clarck, M. S. Jacobs, and S. B. Shohet. 1980. Analysis of factors regulating erythrocyte deformability. J. Clin. Invest. 66:563-573.

21. Clark, M. R., N. Mohandas, S. B. Shohet, R. M. Hoesch, and M. E. Rossi. 1983. Osmotic gradient ektacytometry: comprehensive characterization of red cell volume and surface maintenance. Blood. 61:899-910.

22. Pasvol, G., J. A. Chasis, N. Mohandas, D. J. Anstee, M. J. A. Tanner, and A. H. Merry. 1989. Inhibition of malarial parasite invasion by monoclonal antibodies against glycophorin A correlates with reduction in red cell membrane deformability. Blood. 74:1836-1843.

23. Thompson, S., and A. H. Maddy. 1982. Gel electrophoresis of erythrocyte membrane proteins. In Red Cell Membranes: A Methodological Approach. J. C. Ellory and J. D. Young, editors. Academic Press, New York. 67-93.

24. Tomita, M., and V. T. Marchesi. 1975. Amino-acid sequence and oligosaccharide attachment sites of human erythrocyte glycophorin. Proc. Natl. Acad. Sci. USA. 72:2964-2968.

25. Duke, W. W. 1910. The relation of blood platelets to hemorrhagic disease. J. Am. Med. Assoc. 60:1185-1192.

26. Cronkite, E. P., and D. P. Jackson. 1959. The use of platelet transfusions in hemorrhagic disease. In Progress in Hematology. Vol. 2. L. M. Tocantins, editor. Grune and Stratton, New York. 239-257. 
27. Jackson, D. P., D. K. Sorensen, E. P. Cronkite, V. P. Bond, and T. M. Fliedner. 1959. Effectiveness of transfusions of fresh and lyophilized platelets in controlling bleeding due to thrombocytopenia. J. Clin. Invest. 38:1689-1697.

28. Hjort, P. F., V. Perman, and E. P. Cronkite. 1959. Fresh, disintegrated platelets in radiation thrombocytopenia: correction of prothrombin consumption without correction of bleeding. Proc. Soc. Exp. Biol. Med. 102:31-35.

29. Schulman, I., Z. Currimbhoy, C. H. Smith, M. E. Erlandson, J. B. Schorr, E. Fort, and J. Wehman. 1959. Phosphatides as platelet substitutes in blood coagulation. Ann. NY Acad. Sci. 75:195. (Abstr.)

30. Kahn, R. A., R. W. Allen, and J. Baldassare. 1985. Alternate sources and substitutes for therapeutic blood components. Blood. 66:1-12.

31. Schiffer, C. A., J. Aisner, and P. H. Wiernik. 1978. Frozen autologous platelet transfusion for patients with leukemia. N. Engl. J. Med. 299:7-12.

32. Parise, L. V., and D. R. Phillips. 1985. Platelet membrane glycoprotein IIb-IIIa complex incorporated into phospholipid vesicles: preparation and morphology. J. Biol. Chem. 260:1750-1756.

33. Baldassare, J. J., R. A. Kahn, M. A. Knipp, and P. J. Newman. 1988. Reconstitution of platelet proteins into phospholipid vesicles. Functional proteoliposomes. J. Clin. Invest. 75:35-39.

34. Rybak, M. E. 1986. Glycoproteins IIb and IIIa and platelet thrombospondin in a liposome model of platelet aggregation. Thromb. Haemostasis. 55:240-245.

35. Ryback, M. E., and L. Renzulli. 1990. A liposome based platelet substitute, the plateletsome, with hemostatic efficacy. Blood. Suppl. 1:473a. (Abstr.)

36. McFarland, J. G., and R. H. Aster. 1991. Platelet immunology and the HLA system. In Principles of Transfusion Medicine. Williams \& Wilkins Co. Baltimore. 193-204.

37. Newman, P. J. 1991. Platelet GPIIb-IIIa: Molecular variations and alloantigens. Thromb. Haemostasis. 66:111-118.
38. Lopez, J. A., and E. H. Ludwig. 1991. Molecular basis of platelet glycoprotein Ib polymorphism. Clin. Res. 39:327a. (Abstr.)

39. Kiefel, V., S. Santoso, B. Katzmann, and Mueller-Eckhardt. 1989. The $\mathrm{Br}^{\mathrm{a}} / \mathrm{Br}^{\mathrm{b}}$ alloantigen system on human platelets. Blood. 73:2219-2223.

40. Roy, S. N., R. Pocyk, B. J. Kudryk, and C. M. Redman. 1991. Assembly and secretion of recombinant human fibrinogen. J. Biol. Chem. 266:4758-4763.

41. Feron, V. J., H. P. Til, F. de Vrijer, R. A. Woutersen, F. R. Casee, and P. J. van Bladeren. 1991. Aldehydes: occurrence, carcinogenic potential, mechanism of action and risk assessment. Mutat. Res. 259:363-385.

42. Anstee, D. J. 1990. Blood group-active surface molecules of the human red blood cell. Vox Sang. 58:1-20.

43. Suzuki, T., and G. L. Dale. 1987. Biotinylated erythrocytes. In vivo survival and in vitro recovery. Blood. 70:791-795.

44. Walsh, P. N., and A. H. Schmaier. 1987. Platelet-coagulant protein interactions. In Hemostasis and Thrombosis: Basic Principles and Clinical Practice. R. W. Colman, J. Hirsh, V. J. Marder, and E. W. Salzman, editors. J. B. Lippincott Company, Philadelphia. 689-703.

45. Zwaal, R. F. A., E. M. Bevers, P. Comfurius, J. Rosing, R. H. J. Tilly, and P. F. J. Verhallen. 1989. Loss of membrane phospholipid asymmetry during activation of blood platelets and sickled red cells: mechanism and physiological significance. Mol. Cell. Biochem. 91:23-31.

46. Santos, M. T., J. Valles, A. J. Marcus, L. B. Safier, M. J. Broekman, N. Islam, H. G. Ullman, A. M. Elvoa, and J. Aznar. 1991. Enhancement of platelet reactivity and modulation of eicosanoid production by intact erythrocytes. A new approach to platelet activation and recruitment. J. Clin. Invest. 87:571-591.

47. Houston, D. S., P. Robinson, and J. M. Gerrard. 1990. Inhibition of intravascular platelet aggregation by endothelium-derived relaxing factor: reversal by red blood cells. Blood. 76:953-958. 